\title{
Reducing the Burden of Iron Deficiency Anemia in Cote D'Ivoire through fortification
}

\author{
Alberto Prieto-Patron ${ }^{1 *}$, Magalie Sabatier ${ }^{1}$, Zsuzsa V. Hutton ${ }^{1}$, Giovanni Fattore ${ }^{2}$, Patrick Detzel ${ }^{1 *}$. \\ ${ }^{1}$ Nestlé Research Center, Vers-chez-les-Blanc, Switzerland; alberto.prietopatron@rdls.nestle.com (A.P.P.); \\ Magalie.Sabatier@rdls.nestle.com (M.S.); zsuzsav.hutton@rdls.nestle.com (Z.H.); \\ Patrick.Detzel@rdls.nestle.com (PRD) \\ 2 Bocconi University, Department of Policy Analysis and Public Management, CERGAS - Centre for \\ Research in Healthcare Management, Milano, Italy; giovanni.fattore@unibocconi.it \\ *Correspondence: alberto.prietopatron@rdls.nestle.com; patrick.detzel.@rdls.nestle.com; Tel.: +41 21 924- \\ 6309
}

\begin{abstract}
Iron deficiency anemia (IDA) is highly prevalent in the Cote d'Ivoire, and has severe health and economic consequences. In this paper, we apply a health economic model to quantify the burden of IDA, and the contribution of nation-wide mandatory iron fortification of wheat flour and voluntary iron fortification of condiments to the reduction of this burden. The analysis for the population from six months to 64 years builds on published reviews and publicly available datasets, and is stratified by age-groups and socio-economic strata. Without the impact of these fortification strategies, the annual burden of IDA is estimated at 242,100 disability adjusted life years (DALYs) and 978.1 million USD. Wheat flour and condiment fortification contributed to a reduction of the IDA burden by approximately $5 \%$ each. In places with high prevalence of malaria and environmental factors, such as the Côte D'Ivoire, policy makers should combine nutritional intervention with infectious disease prevention and environmental factors. The findings of this study provide additional input for policy makers about the magnitude of the impact and can support the conception of future fortification strategies.
\end{abstract}

Keywords: economic evaluation, micronutrient fortification, iron deficiency anemia, Cote d'Ivoire, model, impact, DALYs

\section{Introduction}

In 2010 an estimated one-third of the world population was affected by anemia [1, 2], resulting in the loss of 68 million disability-adjusted life years (DALYs) during that year [1]. There has been progress in reducing the prevalence of anemia worldwide from $40.2 \%$ to $32.9 \%$ from 1990 to 2010 [1]. Southeast Asia recorded the greatest improvements, whereas sub-Saharan Africa achieved the lowest progress [1]. Despite the improvement still over half of the burden of anemia arises from iron deficiency, accounting for over 35 million DALYs lost [2,3]. This estimation is based on a widely used attribution of $50 \%$ of anemia to iron deficiency and it has recently been challenged by a recent meta-analysis of 23 national surveys, which concluded that only about $25 \%$ of anemia among preschool children is attributable to iron deficiency, and 37\% among women in reproductive age [4]. However, irondeficiency-anemia (IDA) continues to be a significant public health concern.

The burden associated with IDA is the highest among nutritional deficiencies around the world surpassing all other nutritional deficiencies combined including protein-energy malnutrition [3]. In the Cote d'Ivoire, iron deficiency (41-63\%) and IDA (20-39\%) are highly prevalent among women and children [5]. 
Although income growth should induce improved nutritional status on the long-run, evidence from low-income countries showed a low income elasticity of micro-nutrient demand, which means that income growth leads only to a marginal contribution to curb IDA prevalence, thus highlighting the need for additional strategies to accelerate the decline [6, 7]. Some governments implemented, in addition to educational, sanitary and health interventions to prevent and treat parasitic diseases, mandatory mass fortification of staple foods and iron supplementation programs [8-10]. In the Philippines a study looking at the impact of mandatory fortification between 2003 and 2013 showed that the prevalence of anemia in Filipino children aged 1-4 years was reduced from $37.4 \%$ to $11.3 \%$ [11]. This was due to a combination of strategies that included food fortification and infection control. In Costa Rica, fortification of wheat flour and milk resulted in a marked reduction in anemia among women and children [12]. In particular, iron deficiency among children declined from $26.9 \%$ to $6.8 \%$ and IDA declined from $6.2 \%$ at baseline to undetectable levels. Malaysia, Colombia and China drastic reduction on IDA has been associated with fortification, government programs increasing improving nutritional dietary intake and income growth.

In the Cote d'Ivoire, iron fortification of wheat flour became mandatory in 2007 as part of the fortification policy [9]. Despite its mandatory nature, subsequent surveys evaluating the impact of this policy showed that only around $50 \%$ of the flour samples complied with the mandated levels of iron fortification limiting the potential impact $[10,16]$. Rohner et al. conclude that despite this policy the prevalence of IDA remains high and that there is still a need for additional iron-fortified food vehicles to reduce the burden [10].

Next to staple and processed foods, condiments and seasonings are promising vehicles for iron fortification [17-19], because even vulnerable population groups consume these regularly. Data from a recent Fortification Rapid Assessment Tool (FRAT) survey across 12 countries in sub-Saharan Africa indicated that between $79 \%$ and $99 \%$ of respondents consumed bouillon cubes [20]. Some programs in Asia and Africa now use condiments and seasonings as vehicles to address micronutrient deficiencies [21, 22].

In the Cote d'Ivoire, a cross-sectional survey showed that $97 \%$ of women in child-bearing age consumed bouillon cubes [10]. The estimated mean consumption was $3.7 \mathrm{~g} /$ day among women of child-bearing age and $1.4 \mathrm{~g} /$ day among 6-23 month-old children. Although iron fortification of condiments in the Cote d'Ivoire is not mandatory, the voluntary iron fortification of the main commercial brand began in May 2013, adding $2.1 \mathrm{mg}$ of iron per $3.3 \mathrm{gr}$ of bouillon, meaning that at least $90 \%$ of bouillons sold in the country has been fortified since.

Burden of disease studies provides important scientific information to decision makers about the scale of a public health problem and its consequences. Analyzing to what extent different policies can help to alleviate the problem helps to compare alternatives. The objectives of this study are firstly, to estimate the burden of Iron Deficiency Anemia as of 2014 in Cote D'Ivoire, and secondly to assess the contribution of iron-fortified flour and bouillon cubes to the reduction of the burden.

\section{Materials and Methods}

The burden of IDA corresponds only to the burden of anemia attributed to iron deficiency. To estimate the annual burden of IDA as of 2014. We used prevalence figures reported in the National Demographic and Health Survey (Enquète Démographique et de Santé, EDS) 2011-2012 and 
extrapolated the prevalence of anemia to the population registered in the Ivorian Census in 2014. Because the voluntary fortification program started after EDS, in May 2013, we adjusted the prevalence of IDA to take into account the additional iron intake at the population level from fortified bouillons cubes. Our estimation of the contribution of bouillon cubes derives from estimating the burden with and without the adjustment in the prevalence. The mandatory fortification program of flour started in 2007 much before EDS was carried out. Therefore, the full effect of the additional iron flour fortification was captured in the survey. To estimate the contribution of flour fortification, we estimated how much the prevalence of IDA would have increased if the iron provided from flour would not be there. The sequence of the above points is summarized in Figure 1.

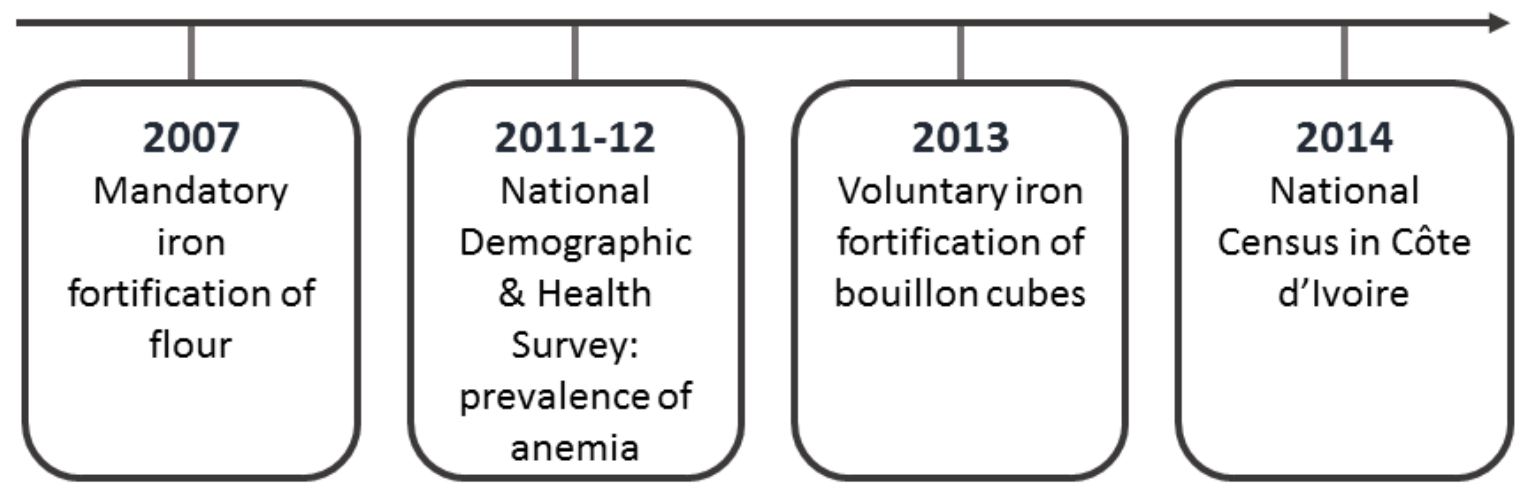

Figure 1. Sequence of fortification interventions and national surveys in Cote d'Ivoire.

The following paragraphs explain details of the model, the population subgroups used in the analysis, the prevalence estimation and the considered impacts of fortification which allows us to estimate the contribution of flour and condiment iron fortification to the reduction of the health and economic burden.

\subsection{Model}

To estimate the health and economic burden of IDA we adopted the comparative risk assessment model [20]. For children under 5 years old, we followed an approach proposed by Wieser et al. [24]. For adults, we use similar methodology as Bagriansky et al. [25] and Alcazar [26]. For school age children, we built a model for the poorer learning and schooling outcomes linked to anemia [27-31] and its consequence on future productivity [32]. The model considers the prevalence of iron deficiency anemia for each specific population group, as well as its health consequences and estimates the economic and health burden of the disease (Figure 2).

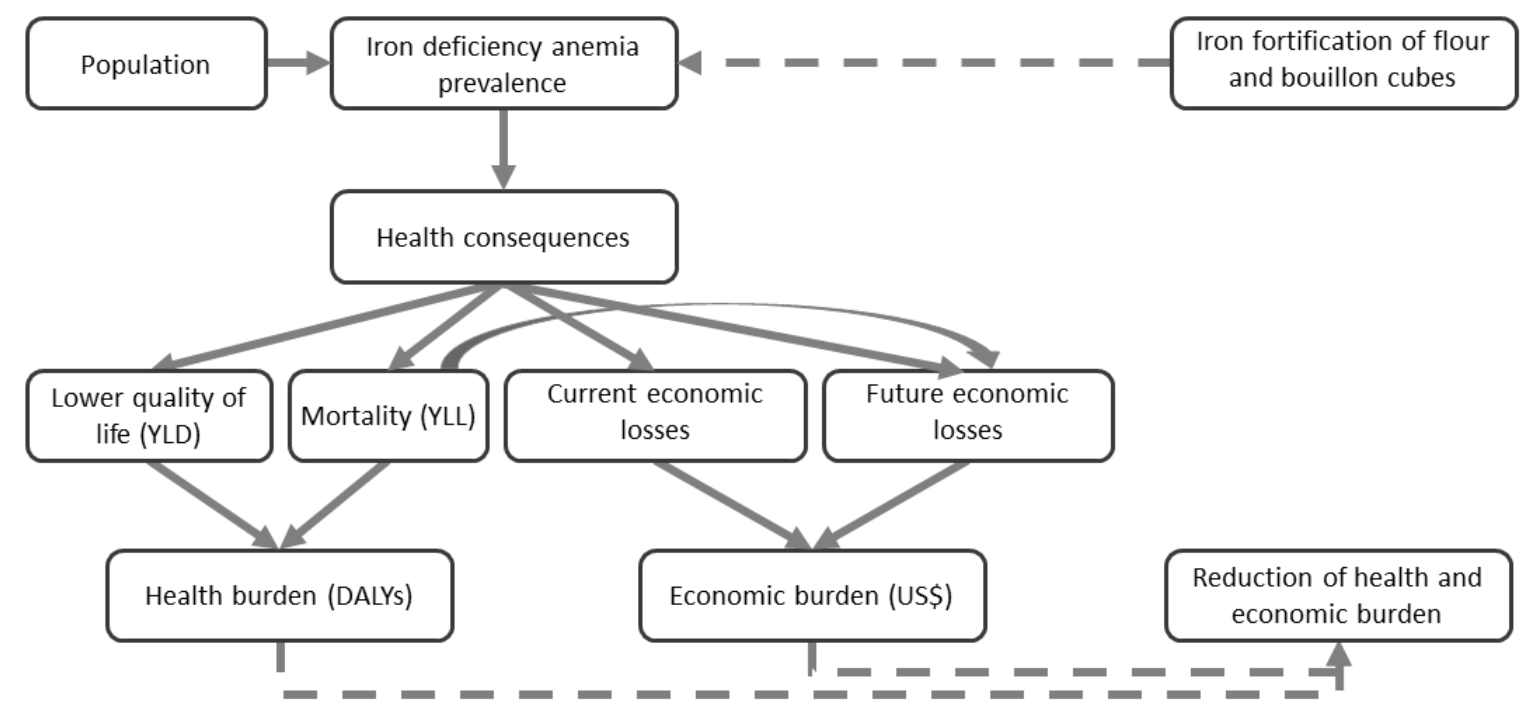

Figure 2. Estimating the economic and health burden of IDA. 


\subsection{Population}

We considered in our model 21 million habitants between the age of 6 months and 64 years based on 2014 Ivorian Census [33]. Because both the prevalence and the health consequences of IDA differ by age, gender and socio-economic status, we split the population in our analysis into several groups. By age, we divide the population into three main groups: pre-school age children 6 months to 4 years old (2.7 million); school-age children 5 to 14 years old (6.2 million) and; adults 15 to 64 years old (12.1 million). Within these age groups, we created additional subgroups. For pre-school age children, we modeled separately children 6 to 23 months and 24 to 59 months. For school age children, we considered each year cohort separately and distinguished between boys and girls. For adults, we created four sub-groups: men, non-pregnant women in reproductive age, pregnant women and older women. Furthermore, we clustered each subgroup into 10 socio economic strata (SES).

\subsection{Prevalence of Iron Deficiency Anemia}

We used raw data from the National Demographic and Health Survey (in French, Enquète Démographique et de Santé, EDS) 2011-12 in the Cote d'Ivoire to estimate the prevalence of anemia in each population subgroup and SES. This is the only survey in the Cote d'Ivoire which included population-wide information on hemoglobin concentrations from blood tests of pre-school age children (6 to 59 months) and adult women and men (15 to 49 years old). However, hemoglobin data were not available for school-aged children (5 to 14 year old) in the EDS 2012. Therefore, we imputed the data based on results from a local study in Cote d'Ivoire that reported the prevalence of IDA in older versus younger children [5].

In our analysis, we were interested in modeling the prevalence of IDA by each SES cluster within each population subgroup. However, EDS was designed to estimate the prevalence of anemia at national level. Therefore, we used the regression analysis between hemoglobin and wealth index in each population subgroup to determine the mean hemoglobin concentration for each SES cluster. Then, using the mean, the standard deviation and assuming that hemoglobin concentrations are normally distributed, we were able to determine the prevalence and severity of anemia in each SES and population sub-group.

In our model we adopted the figure proposed by Asorbayire et al. [5] and Kassebaum et al. [1] for the proportions of anemia due to iron deficiency which are the most referenced estimates in the literature. These were $64 \%$ for children under five years, $45 \%$ for school-age children, 39\% for women and $18 \%$ for adult men. A caveat must be made that there is ongoing discussion in the scientific world about the best and most appropriate methods of determining what proportion of anemia can be attributed to iron deficiency in different geographies. This is discussed in detail in the recent publications of the BRINDA group [34-36]. Furthermore, Perty, et al [4] argues that the Kassebaum estimates are probably too high and suggest considerably lower attributable fractions. The purpose of our analysis is not to engage in the scientific discussions around attributable fractions. We acknowledge that the Asorbayire et al. [5] and Kassebaum et al. [1] estimates have their limitations, therefore we also run the analysis with figures of Petry et al [4], which is referred to in the discussion and full detail tables are presented in the appendix D. The analysis presented in this paper details results with the Asorbaye and Kassebaum figures. The uncertainty around the fraction of anemia attributable to iron deficiency as proposed by these authors is considered in the probabilistic sensitivity analysis allowing a variation of the parameters following a beta distribution.

Table 1. Prevalence of anemia and iron deficiency anemia for the age groups considered in the model

\begin{tabular}{cccccc}
\hline Age group & $\begin{array}{c}\text { Anemia } \\
\text { prevalence }\end{array}$ & $\begin{array}{c}\text { Share due } \\
\text { to ID }\end{array}$ & $\begin{array}{c}\text { IDA } \\
\text { estimate }\end{array}$ & $\begin{array}{c}\text { IDA highest } \\
\text { SES }\end{array}$ & $\begin{array}{c}\text { IDA Lowest } \\
\text { SES }\end{array}$ \\
\hline Pre-school children & $74.8 \%$ & $64.0 \%$ & $47.9 \%$ & $37.8 \%$ & $52.5 \%$ \\
School age children & $56.1 \%$ & $49.0 \%$ & $27.5 \%$ & $21.7 \%$ & $30.1 \%$ \\
Women & $54.9 \%$ & $39.0 \%$ & $21.4 \%$ & $18.8 \%$ & $22.3 \%$ \\
Men & $29.7 \%$ & $18.0 \%$ & $5.3 \%$ & $4.5 \%$ & $6.0 \%$ \\
\hline
\end{tabular}


IDA: iron deficiency anemia; ID: iron deficiency: SES: socioeconomic strata; Pre-school children from 0.5 to 4 years old; School age children from 5 to 14 years old: Adults men and women from 15 to 64 years old.

The prevalence of anemia was estimated from row data of the Demographic and Health Survey 2011-12 in Côte D'Ivoire. The share of iron deficiency anemia is estimated based on Kassebaum, et al and Asorbayire, et al. $[1,5]$

\subsection{Health consequences of IDA}

The three health consequences of IDA that we considered in the model are: (a) cognitive impairment in infancy between 6 and 23 months, (b) child mortality between 6 months to 59 months, and (c) reduced physical activity (weakness and fatigue) for all age groups [37-41]. Cognitive impairment in early childhood and child mortality are irreversible health consequences of IDA, while reduced physical activity can be reverted once hemoglobin levels are increased.

We did not include the consequences of maternal IDA on the increased risk of preterm labor, low infant birth weight, infantile anemia and maternal mortality. We did so partly because data on these parameters are vacuous. Furthermore, it would have added considerable additional complexity to the model. Therefore, our estimation remains partial and conservative on costs.

\subsection{The health burden of IDA}

To quantify the burden of the health consequences of IDA we applied the methodology established by the Global Burden of Disease and used the disability weights of Stein et al. adjusted by Plessow et al. [2, 42-44]. Table 2 summarizes the key figures used in the calculus. For estimating the cognitive decline due to moderate and severe IDA among 6-23 months old infants and the mortality of 6-59 month-old infants we follow the approach of Wieser et al., consider estimates of Lozoff et al. (2006) on the reduction of Intelligence Quotient (IQ) and of Brabin et al. (2001) on child mortality [24, 37, 39].

Table 2. Parameters used for estimating the health burden (in DALYs) due to IDA by Plessow et al. [35].

\begin{tabular}{|c|c|c|c|c|}
\hline Health consequence & Severity & $\begin{array}{c}\text { Disability } \\
\text { Weights }\end{array}$ & Age-group & Source \\
\hline \multirow[t]{2}{*}{$\begin{array}{c}\text { Impaired physical } \\
\text { activity }\end{array}$} & Mild & 0.005 & All & $\begin{array}{l}\text { Solomon J. A et al. } \\
\text { Plessow et al. }\end{array}$ \\
\hline & $\begin{array}{l}\text { Moderate } \\
\text { Severe }\end{array}$ & $\begin{array}{l}0.058 \\
0.164\end{array}$ & $\begin{array}{l}\text { All } \\
\text { All }\end{array}$ & $\begin{array}{l}\text { Murray et al. } \\
{[2,39,40,42]}\end{array}$ \\
\hline Cognitive impairment & Moderate & 0.0078 & $\begin{array}{l}\text { 6-23 months } \\
\text { (pre-school children) } \\
\text { 6-23 months } \\
\text { (pre-school children) }\end{array}$ & $\begin{array}{c}\text { Plessow et al. } \\
\text { Murray et al. } \\
{[39,40,42]}\end{array}$ \\
\hline All-cause mortality & Severe & 1.0 & $\begin{array}{l}\text { 6-59 months } \\
\text { (pre-school children) }\end{array}$ & $\begin{array}{c}\text { Plessow et al. } \\
\text { Murray et al. } \\
{[39,40,42]}\end{array}$ \\
\hline
\end{tabular}

In the model, we calculate the life-long burden of the irreversible health consequences of IDA (cognitive impairment and child mortality) beyond year 2014 (the modelled year). For child mortality, we consider the total years of life lost (remaining life expectancy at children's age). For mental impairment we took into account the estimated number of years lived with this condition. In the model for the reversible health consequence, namely reduced physical activity, only the current year was considered.

\subsection{The economic burden of IDA}

In Table 3, we present the key parameters used to quantify the economic burden associated with the health consequences of IDA. Our economic model is inspired by Horton and Ross [46]. Similar to them, we only consider production losses in estimating the economic burden. We did not include direct medical costs because only a small fraction of IDA is treated in the Ivorian setting and therefore the costs are negligible. 
Table 3. Parameters to estimate the production losses (economic burden) linked with IDA.

\begin{tabular}{|c|c|c|}
\hline Parameter & Value & Source \\
\hline Life expectancy & 58 years & World Factbook [47] \\
\hline Age to begin working life & 15 years & World Bank [48] \\
\hline Age of ending working life & 64 years & World Bank [48] \\
\hline Mean monthly wage & $65,575 \mathrm{XOF}$ & National Statistics Cote D'Ivoire [49] \\
\hline Monetary discount rate & $3 \%$ & Smith [50] \\
\hline Expected income growth & $3.5 \%$ & World Bank [51] \\
\hline Work force participation (net) & $63 \%$ & World Bank [48] \\
\hline Income distribution & $\begin{array}{l}\text { SES } 1: 1.9 \% \text { to } \\
\text { SES } 10: 34.8 \%\end{array}$ & UNI-WIDER [52] \\
\hline $\begin{array}{l}\text { Unadjusted intergeneration income } \\
\text { correlation }\end{array}$ & 0.55 & Black, Solon $[53,54]$ \\
\hline $\begin{array}{l}\text { Education adjusted intergeneration } \\
\text { income correlation }\end{array}$ & 0.35 & Black [53] \\
\hline Returns on education & $10.9 \%$ & Psacharopoulos [32] \\
\hline $\begin{array}{l}\text { Impact of anemia on school } \\
\text { performance }\end{array}$ & $-10 \%$ & Soemantri et al., Hutchinson et al. $[29,30]$ \\
\hline $\begin{array}{l}\text { Impact of anemia on school } \\
\text { attendance }\end{array}$ & $-5.3 \%$ & $\begin{array}{l}\text { Soemantri et al., Hutchinson et al., Bobonis et } \\
\text { al., Walker et al. [27, 29-31] }\end{array}$ \\
\hline $\begin{array}{l}\text { Relative risk of school absenteeism on } \\
\text { school drop-outs }\end{array}$ & 1.8 & Walker et al [31] \\
\hline $\begin{array}{c}\text { Impact of } 1 \text { standard deviation } \\
\text { reduction in cognitive score on future } \\
\text { wages }\end{array}$ & $-8 \%$ & Psacharopoulos [55] \\
\hline $\begin{array}{l}\text { Impact of IDA on productivity of } \\
\text { moderate manual labor }\end{array}$ & $-5 \%$ & Basta [53] \\
\hline $\begin{array}{l}\text { Impact of IDA on productivity of } \\
\text { intense manual labor }\end{array}$ & $-17 \%$ & Basta [53] \\
\hline
\end{tabular}

We quantify two types of production losses, those that are occurring in the year that we are modeling and those, which take place in the future. In the model, current production losses encompass lower wages of workers due to inferior productivity because of weakness and fatigue associated with anemia. For estimating future production losses associated with IDA the model considers lower human capital accumulation, originated from mortality among 0.5-4 year-old children, cognitive impairment of 6-23 month-old pre-school children, and lower retention of knowledge and school drop-out of 5-14 year old children. To compute the future production losses of pre-school children, we followed the approach developed by Wieser et al. [24] and Plessow et al. [43]. Most of the costs incurred by this age group arise from cognitive impairment due to moderate and severe anemia reflected in reduced future wages. To estimate the losses due to cognitive impairment we first estimate the IQ loss for infants suffering severe and moderate anemia [39]. Then based on the association between IQ and wages we calculate the expected average wage difference associated with lower IQ, multiply by the expected years that a child would work and discount to obtain the net present value. To predict baseline future wages, Wieser et al. used the average wage for the country alongside an expected growth trajectory [24].

To estimate the economic burden of IDA for children aged 5-14 years, we count with the negative effect of anemia on school learning and consider 10\% lower retention of knowledge, higher school absenteeism and early school dropouts leading to reduced life-long productivity (Table 3) [30, 31]. For this, we applied returns on education figures originating from sub-Saharan Africa (Table 3) [32]. In estimating the productivity loss for adults, we calculated lower productivity of manual labor using figures of Basta et al. (Table 3), similarly to Horton et al. [46, 56]. Additionally, we took into account the prevalence of IDA by SES, age, gender and for women by pregnancy status.

In order to obtain a more precise estimation of production losses, we took into account income inequality by SES, as well as future wage inequalities using estimates of intergenerational income 
correlation $[2,52]$. The calculation of production losses linked to lower school performance is detailed in Appendix A.

\subsection{Calculating the reduction of the health and economic burden linked to iron fortification}

We considered the following aspects to estimate the impact of fortification. First, we calculated the additional milligrams of iron intake by age-groups because of the fortification intervention. We based our estimation on consumption data by age-group and fortification levels of the food vehicle. Second, we translated the additional milligrams of iron into an estimated increase in hemoglobin based on published effectiveness of the iron compound used, and adjusted it for other bioavailability aspects, such as the rest of the diet. Third, we estimated the hypothetical prevalence of IDA based on population level hemoglobin distribution taking into account the fortification effect. Finally, we estimated the burden for the hypothetical IDA prevalence.

Table 4. Parameters used to estimate the effect of iron fortified flour and bouillon cubes on IDA.

\begin{tabular}{|c|c|c|c|}
\hline Parameter & Age-group & Value & Source \\
\hline \multicolumn{4}{|c|}{ Additional iron intake } \\
\hline \multirow{5}{*}{$\begin{array}{c}\text { Wheat flour } \\
\text { Bouillon } \\
\text { cubes }\end{array}$} & 6-23 months & $0.74 \mathrm{mg} /$ day & \multirow{4}{*}{ Own calculation based on Rohner et al. [10] } \\
\hline & adult women & $2.63 \mathrm{mg} /$ day & \\
\hline & 6-23 months & $0.89 \mathrm{mg} /$ day & \\
\hline & adult women & $2.35 \mathrm{mg} /$ day & \\
\hline & & Increase in & oglobin \\
\hline \multirow{3}{*}{ Wheat flour } & 6-23 months & $0.561 \mathrm{~g} / \mathrm{L}$ & \multirow{6}{*}{$\begin{array}{l}\text { Own calculation based on: Hess et al., } \\
\text { Winichangoon et al. }[57,58]\end{array}$} \\
\hline & 24-59 months & $0.798 \mathrm{~g} / \mathrm{L}$ & \\
\hline & 5-64 years & $1.034 \mathrm{~g} / \mathrm{L}$ & \\
\hline \multirow{3}{*}{$\begin{array}{l}\text { Bouillon } \\
\text { cubes }\end{array}$} & 6-23 months & $0.673 \mathrm{~g} / \mathrm{L}$ & \\
\hline & 24-59 months & $0.799 \mathrm{~g} / \mathrm{L}$ & \\
\hline & 5-64 years & $0.924 \mathrm{~g} / \mathrm{L}$ & \\
\hline
\end{tabular}

The input parameters for the model are summarized in Table 4. The consumption of fortified wheat flour and the levels of iron fortification was calculated based on a survey from Cote d'Ivoire [10]. For condiments an annual consumption of 6 billion servings (unpublished data) and $2.1 \mathrm{mg}$ iron per serving is considered.

The impact of iron-fortification on increasing hemoglobin levels was calculated based on the metaanalysis by Hess et al. [57]. This meta-analysis reported an enhanced hemoglobin concentration of $7.4 \mathrm{~g} / \mathrm{L}$ in the study population (aged 5-50 years) by adding on average $10.6 \pm 4.7 \mathrm{mg}$ of iron to the diet per day.

Considering the fortification dose per serving of bouillon cubes and the average number of servings consumed per day per person (1.1) the effect over several months could result in a hemoglobin increase of $1.6 \mathrm{~g} / \mathrm{L}$. However, because there is a difference in the bioavailability (percentage of the iron absorbed by the body) of different iron compounds used in the clinical trials, we selected a subsample of publications [58-60] from the Hess review that used iron pyrophosphate or similar compound suitable for the fortification of bouillon cubes. As a consequence, the impact of a condiment (i.e. bouillon cubes) fortified at $15 \%$ of the Codex Nutrient Reference Values (NRVs) (i.e. $15 \%$ of $14 \mathrm{mg}=2.1 \mathrm{mg}$ iron per serving) consumed at 1.1 servings per day over a long period of time could result in a hemoglobin increase of $0.924 \mathrm{~g} / \mathrm{L}$ in adults and school-aged children. For children, 6-23 months the reported consumption of bouillon is $1.4 \mathrm{~g} /$ day [10] which represent 0.891 additional $\mathrm{mg}$ of iron a day equivalent to $12.4 \% \mathrm{NRV}$. This could lead to an increase of the hemoglobin concentration of $0.673 \mathrm{~g} / \mathrm{L}$. In the absence of information on what fortifying agent is used exactly in wheat flour we assumed similar bioavailability as for the condiments. The approach detailed above for condiments was applied also to wheat flour adjusting for level of consumption and fortification. 


\section{Results}

Table 5 presents the estimated economic burden of IDA following the introduction of mandatory flour fortification, and later voluntary condiment fortification. Table 6 presents for the same periods both the discounted and the undiscounted health burden. The results presented in Tables 5 and 6 build on on figures of Table 1, using estimates of Kassebaum, et al. and Asorbayire, et al. [1,5] for the attribution of anemia due to ID. Additionally we present figures for the the attribution of anemia due to ID as published by Petry et al. in Appendix D ( Tables D1 and D2) [4].

Table 5. Economic burden: Production losses before and after iron fortification of wheat flour and condiments by age-group.

\begin{tabular}{|c|c|c|c|c|}
\hline & $\begin{array}{l}\text { Pre-school } \\
\text { children }\end{array}$ & $\begin{array}{c}\text { School-aged } \\
\text { children }\end{array}$ & Adults & Total \\
\hline & \multicolumn{4}{|c|}{ million USD } \\
\hline $\begin{array}{l}\text { After condiment \& flour fortification } \\
\qquad(\text { mean }[95 \% \mathrm{CI}])\end{array}$ & $\begin{array}{c}411 \\
{[255.5: 623.1]}\end{array}$ & $\begin{array}{c}444.3 \\
{[221: 750.6]}\end{array}$ & $\begin{array}{c}34.6 \\
{[26.1: 44.2]}\end{array}$ & $\begin{array}{c}889.9 \\
{[581.5: 1306.8]}\end{array}$ \\
\hline $\begin{array}{l}\text { After flour and before condiment } \\
\text { fortification (mean }(95 \% \mathrm{CI}))\end{array}$ & $\begin{array}{c}425.4 \\
{[264.8: 644.5]}\end{array}$ & $\begin{array}{c}471.5 \\
{[234.6: 796.3]}\end{array}$ & $\begin{array}{c}36.3 \\
{[27.5: 46.4]}\end{array}$ & $\begin{array}{c}933.1 \\
{[609.2: 1371]}\end{array}$ \\
\hline $\begin{array}{l}\text { Before flour fortification (mean } \\
\qquad(95 \% \mathrm{CI}))\end{array}$ & $\begin{array}{c}437.6 \\
{[272.6: 662.6]}\end{array}$ & $\begin{array}{c}502.4 \\
{[250.1: 847]}\end{array}$ & $\begin{array}{c}38.2 \\
{[28.9: 48.8]}\end{array}$ & $\begin{array}{c}978.1 \\
{[636.8: 1438.1]}\end{array}$ \\
\hline $\begin{array}{l}\text { Absolute change attributable to flour } \\
\text { fortification (mean) }\end{array}$ & 12.2 & 30.9 & 1.9 & 45 \\
\hline \multirow[t]{2}{*}{$\begin{array}{l}\text { Absolute change attributable to } \\
\text { condiment fortification (mean) }\end{array}$} & 14.4 & 27.2 & 1.7 & 43.2 \\
\hline & & $\%$ change & & \\
\hline $\begin{array}{l}\text { Reduction attributable to flour } \\
\text { fortification }\end{array}$ & $2.8 \%$ & $6.1 \%$ & $5.0 \%$ & $4.6 \%$ \\
\hline $\begin{array}{l}\text { Reduction attributable to condiment } \\
\text { fortification }\end{array}$ & $3.4 \%$ & $5.8 \%$ & $4.7 \%$ & $4.6 \%$ \\
\hline
\end{tabular}

CI: confidence interval. This refers to constructed $95 \%$ confidence intervals as calculated in the probabilistic sensitivity analysis. Pre-school children: 0.5 to 4 years; School age children: 5 to 14 years Adult men and women: 15 to 64 years.

Table 6. Health burden: disability adjusted life years (DALYs) before and after iron fortification of wheat flour and condiments by age-group.

\begin{tabular}{|c|c|c|c|c|}
\hline & $\begin{array}{l}\text { Pre-school } \\
\text { children }\end{array}$ & $\begin{array}{c}\text { School- } \\
\text { aged } \\
\text { children }\end{array}$ & Adults & Total \\
\hline \multicolumn{5}{|c|}{ DISCOUNTED HEALTH BURDEN } \\
\hline & \multicolumn{4}{|c|}{ ‘000 DALYs } \\
\hline After condiment \& flour fortification & 121.9 & 43.8 & 49.1 & 214.7 \\
\hline$($ mean $[95 \% \mathrm{CI}])$ & {$[92.4: 157.8]$} & {$[25.3: 66.5]$} & {$[29.2: 74]$} & {$[156.7: 286.2]$} \\
\hline After flour and before condiment & 128.3 & 47.3 & 52.6 & 228.1 \\
\hline fortification (mean [95\%CI]) & {$[97.5: 165.8]$} & {$[27.4: 71.7]$} & {$[31.4: 79.2]$} & {$[166.7: 304]$} \\
\hline Before flour fortification (mean $595 \% \mathrm{CI}$ ) & 134.2 & 51.3 & 56.6 & 242.1 \\
\hline Before flour fortification (mean [95\%(1]) & {$[102.4: 173.2]$} & {$[29.9: 77.8]$} & {$[34: 85.1)$} & {$[177.1: 322.8]$} \\
\hline $\begin{array}{l}\text { Absolute change attributable to flour } \\
\text { fortification (mean) }\end{array}$ & 5.9 & 4.1 & 4.1 & 14 \\
\hline \multirow[t]{2}{*}{$\begin{array}{l}\text { Absolute change attributable to } \\
\text { condiment fortification (mean) }\end{array}$} & 6.4 & 3.5 & 3.5 & 13.4 \\
\hline & \multicolumn{4}{|c|}{$\%$ change } \\
\hline $\begin{array}{l}\text { Reduction attributable to flour } \\
\text { fortification }\end{array}$ & $4.4 \%$ & $7.9 \%$ & $7.2 \%$ & $5.8 \%$ \\
\hline $\begin{array}{l}\text { Reduction attributable to condiment } \\
\text { fortification }\end{array}$ & $4.9 \%$ & $7.3 \%$ & $6.7 \%$ & $5.9 \%$ \\
\hline \multicolumn{5}{|c|}{ UNDISCOUNTED HEALTH BURDEN } \\
\hline \multicolumn{5}{|c|}{ ‘000 DALYs } \\
\hline
\end{tabular}




$$
\begin{aligned}
& \text { After condiment \& flour fortification } \\
& \text { (mean }[95 \% \mathrm{CI}] \text { ) } \\
& \text { After flour and before condiment } \\
& \text { fortification [mean }[95 \% \mathrm{CI}])
\end{aligned}
$$

Before flour fortification (mean $[95 \% \mathrm{CI}]$ ) fortification (mean)

Absolute change attributable to condiment fortification (mean)

Reduction attributable to flour fortification

\begin{tabular}{|c|c|c|c|}
\hline & & & \\
\hline 205.4 & 43.8 & 49.1 & 298.2 \\
\hline [153.3 : 267.4] & {$[25.3: 66.5]$} & {$[29.2: 74]$} & [224 : 384.7] \\
\hline 216.4 & 47.3 & 52.6 & 316.3 \\
\hline [161.9: 281.6] & [27.4 : 71.7] & [31.4: 79.2] & [237.9: 407.1] \\
\hline 226.5 & 51.3 & 56.6 & 334.4 \\
\hline [169.7 : 294.1] & [29.9: 77.8$]$ & [34 : 85.1] & [251.7: 430.7] \\
\hline 10 & 4.1 & 4.1 & 18.2 \\
\hline 11.1 & 3.5 & 3.5 & 18 \\
\hline \multicolumn{4}{|c|}{$\%$ change } \\
\hline $4.4 \%$ & $7.9 \%$ & $7.2 \%$ & $5.4 \%$ \\
\hline $5.1 \%$ & $7.3 \%$ & $6.7 \%$ & $5.7 \%$ \\
\hline
\end{tabular}

Reduction attributable to condiment fortification
Absolute change attributable to flour

DALYs: disability adjusted life years; CI: confidence interval. This refers to constructed $95 \%$ confidence intervals as calculated in the probabilistic sensitivity analysis. Pre-school children: 0.5 to 4 years; School age children: 5 to 14 years Adult men and women: 15 to 64 years.

We estimate the annual economic and health burden of IDA in 2014 in the Ivorian population (from 6 months to 64 year-old) to be in the range of 582 and 1,307 million USD and between 156,700 - 286,200 DALYs (Table 5, Table 6). These values include the impact of the additional iron intake from fortifying wheat flour and bouillon cubes. The total average annual cost of IDA, 890 million USD and 214,700 DALYs represents 2.5\% of the Ivorian Gross Domestic Product and a health burden equivalent to 5,141 full life spans in good health lost each year. Pre-school age children (6-59 months) represented $15 \%$ of the population in our model, carrying $46 \%$ of the economic losses and $57 \%$ of the discounted health burden linked to IDA. School age children (5 to 14 years old), represented $29 \%$ of the population carrying $50 \%$ of the economic losses linked to the impact of IDA on schooling and $20 \%$ of the discounted health burden. Overall, adults (men and women 15 to 64 years old) represent $56 \%$ of the population, but only $4 \%$ of the economic losses and $23 \%$ of the discounted health burden.

Overall, mandatory flour fortification as surveyed in 2010 translates into 45 million USD in economic and 14,000 discounted DALY gains in reducing the IDA burden annually (Table 5, Table 6). The introduction of iron-fortified condiments in 2013, based on surveyed consumption and sales volume figures, contributed to a reduction of the annual burden with 43.2 million USD economic and 13,400 DALYs discounted health gains. It appears that the contribution of mandatory wheat flour fortification to the reduction of the IDA burden is in a similar range, with 45 million USD and 14,000 DALYs.

These results are highly dependent on the share of anemia attributed to ID. Although the percentage on the reduction of the burden of IDA due to fortification strategies remains relatively constant, whether we use Kassebaum et al. and Asorbayire et al. or Petry et al. estimates, the burden itself varies substantially. Using the attribution of anemia of $25 \%$ for pre-school age children and $30 \%$ for school age children, 37\% for women and 18\% for men by Petry et al. [4] means that the annual IDA burden is estimated at 491 million USD and 124 thousand DALYs, nearly half of the previous estimate.

\subsection{Probabilistic sensitivity analysis}

We use Monte Carlo simulation to run a multivariate probabilistic sensitivity analysis (PSA) to generate synthetic confidence interval for our estimations. The underlying distributions and confidence intervals of the parameters for the Probabilistic Sensitivity Analysis are summarized in the Appendix B and C. 

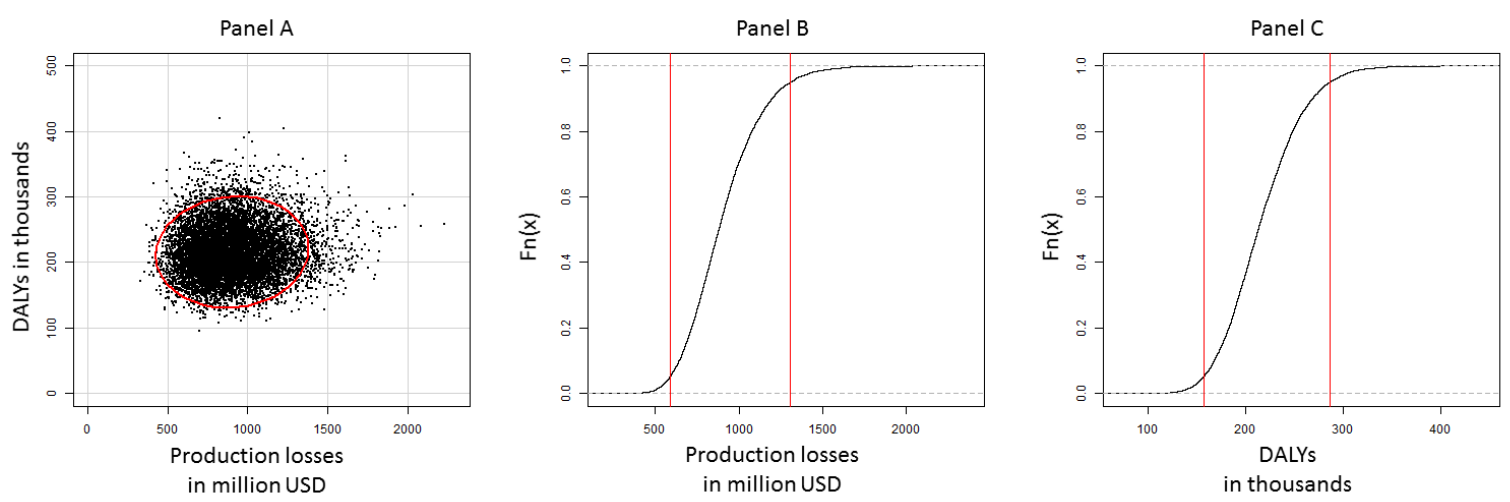

Note: In panel A, 95\% of the estimated values from the Probabilistic Sensitivity Analysis (PSA) are inside the red circle. In panels B and $\mathrm{C}$, the borders set by the vertical red lines encompass $95 \%$ of the estimated PSA values.

Figure 3. Probabilistic sensitivity analysis.

Figure 3 plots the results of 10,000 model runs for the total discounted health and economic burden for 2014, the latter expressed in production losses. The resulting oval area in Panel A circled with red is the set of $95 \%$ chance of falling within the limits. The oval shape indicates that there is more variability in the estimation of the economic burden than in the health burden, which can be explained by the extensive number of influencing variables of the economic part of the model. Panel B shows that the production losses vary in 95\% of the cases from 581 million USD to 1.3 billion USD. Panel C illustrates that in 95\% of the cases the health burden is between 157 and 286 thousand DALYs. The larger synthetic confidence intervals in the production losses result from higher variance on scenarios that predict the economic and wage growth in Cote D'Ivoire. Identical probabilistic sensitivity analyses were ran in all scenarios, details of which are not presented here.

\section{Discussion}

Iron fortification of wheat flour and condiments are strategies to reduce the burden of IDA [21, 57, 61]. Our objective was to provide an estimate on the extent to which these can contribute towards reducing the burden of IDA in Cote D'Ivoire. We modelled the health and economic effects of food fortification for the population from 6 months to 64 years of age by combining different published sources. To our knowledge, this is the first study reporting the contribution of fortified wheat flour and condiment consumption to reducing the burden of IDA in Cote d'Ivoire. We expressed the burden in terms of economic losses (productivity losses in USD) and health impact (number of DALYs).

Horton and Ross's estimation of the burden of iron deficiency in a sample of 10 developing countries was $4 \%$ of the GDP, which is almost, double our estimate [46]. This may arise from our more conservative assumption on the prevalence of iron deficiency anemia. We also excluded the burden of iron deficiency without anemia in the absence of accurate national level figures. Taking into account these differences the magnitude of our estimations is comparable to the above study.

Our model takes into consideration socioeconomic groups for the prevalence of IDA and for the estimation of SES specific wages. This approach is different from previous estimations on the burden of IDA, as they used only mean wages [25]. However, the intake of iron from fortified food vehicles examined in this study is included with a mean value. The level of iron fortification of condiments is standard and survey data on their intake suggests that their daily consumption is relatively stable across different socioeconomic groups. For wheat flour we have to consider that only $50 \%$ of the samples in rural areas were adequately fortified. Furthermore, rural areas are inhabited largely by the poorest $40 \%$ of the households (SES 1-4) and lower socioeconomic strata carry a higher burden of IDA. This in practice means that flour fortification of iron benefits more the urban, hence wealthier households. Using SES-specific wages results in a cost burden that is $12 \%$ lower than using a mean wage (since higher SES groups have higher income but lower IDA prevalence). However, because of the uneven iron intake from wheat flour through SES groups, production losses are likely to be underestimated for this food vehicle in our model. Considering the above points and that we 
calculated with an average fortification level of wheat flour for both urban and rural population groups, our calculation most likely overestimates the impact of wheat flour fortification on reducing the health burden.

There are several limitations to our study. Little data is available on the prevalence of IDA in the Côte d'Ivoire; therefore, we generated a model based on data from the EDS 2012, which only reports anemia levels based on hemoglobin and not iron deficiency anemia. We used figures of Asorbayire and Kassebaum to estimate the share of anemia associated with iron deficiency [1,5]. However, Petry et al. in a recent systematic review suggest that the Kassebaum figures could be too high leading to an overestimation of the burden [4]. Therefore, we have run the model with the figures proposed by Petry et al [4], which would lead to an annual IDA burden estimate of 491 million USD and 124 thousand DALYs (presented in details in appendix D) a much smaller figure than using the Kassebaum et al. and Asorbayire et al. estimates. Although, the percentage in the reduction of the burden is similar under both approaches the base line of the burden varies substantially. There is a need in the scientific community to address these discrepancies as the recommendation in future cost effectiveness analyses of further strategies to reduce the burden would depend on which attribution of anemia to ID is used.

A further limitation of our analysis is that the DHS did not include any information on hemoglobin concentration among school-aged children. Therefore, we had to extrapolate the IDA estimates for this sub-population based on an Ivorian study that compared the prevalence of IDA in older versus younger children [5]. There is the possibility that the data used for our estimates were over- or underreported. Many factors can influence the absorption of iron, such as the deficiency of other micronutrients, the diet or infections [62-65], which may affect our estimates. These uncertainties are reflected to some extent in the PSA, nevertheless considerably more certain estimates could be generated if there were nationwide representative surveys not just registering hemoglobin, but also other biomarkers, which would enable a more accurate estimation of the prevalence of IDA. Our model estimates the production losses linked with education using figures of Psacharoupulos [32]. However, other authors suggest that his estimates are high and propose lower values [66]. It means that our model may lead to an overestimation of the production losses among school-age children. Finally, our study considered the average additional iron intake for each food vehicle on the target population. Using mean values for iron intake is a combination of the level of consumption and the fortification level. This does not allow us to evaluate the appropriateness of the food vehicle based on the coverage of its consumption. For instance, a large portion of the wheat flour consumed in Côte D'Ivoire is in a non-fortifiable form (not processed) compared with bouillons that are fortified. As Aaron et al. emphasize the success of fortification programs is linked with the convenience of the food vehicle, the regularity of intake and of consumption levels, which need to be assessed locally as they vary by country and by food vehicle [67].

Our results support the use of fortified condiments as a potential strategy for addressing IDA in the Côte d'Ivoire in addition to wheat flour iron fortification. Iron fortification of condiments such as bouillon cubes presents a valuable option for improving micronutrient intake at the population level across different socioeconomic groups. Policy makers and nutrition program managers should encourage the use of fortified over non-fortified foods and condiments and ensure that the food industry takes action with respect to the fortification of widely consumed staple foods and condiments [68]. Additionally, because of the uncertainty around the proportion of anemia attributable to iron deficiency, it is important to develop comprehensive approaches to tackle the anemia and IDA burden, where nutrition interventions are complemented with improved sanitation, malaria and other infectious disease prevention and control measures, as in combination they may generate greater benefits than each program individually. Food fortification alone is not sufficient in itself as a nutrition intervention either. The World Health Organization recommends a multi-faceted approach, including fortification, increasing dietary diversity, and supplementation for groups at risk (such as pregnant women) [41]. Nevertheless, the use of widely consumed fortified food vehicles presents a feasible additional food-based mechanism for augmenting iron status in developing countries such as the Côte d'Ivoire. 


\section{Conclusions}

IDA remains a major health problem in the Côte d'Ivoire, resulting in a high health and economic burden representing $2.5 \%$ of the Ivorian Gross Domestic Product and a health burden equivalent to 5,141 full life spans in good health lost each year. If the share of anemia due to iron deficiency was lower as suggested by Petry et al [4] the burden would still be around 1.3\% of the GPD and around 2,600 full life spans lost. As a critical part of the estimation of the burden of IDA depends on the attribution of anemia to ID, there is a need to find broader consensus on the scientific community on the share of anemia due to ID. Despite current fortification strategies, there is still an unmet need for effective interventions that can improve iron status at the population level. In this analysis, we present estimates linked to the iron fortification of wheat flour, which was introduced as a mandatory measure in Cote d'Ivoire, and to condiments, which is a widely consumed food vehicle. Previous studies have shown that although the fortification of wheat flour is mandatory, fortification levels are lagging behind the mandatory levels and consumption levels in a fortifiable form are low. If there was a better vehicle for mandatory fortification the impact could be improved. Our results indicate that iron fortification of condiments (namely, bouillon cubes) presents a feasible strategy for improving iron status complementing mandatory fortification [69]. These findings may provide guidance for policy makers in the conception of future strategies for addressing IDA in the Ivorian population. 


\section{List of abbreviations:}

DALY Disability Adjusted Life Years

IDA Iron Deficiency Anemia

GAIN Global Alliance for Improved Nutrition

FRAT Fortification Rapid Assessment Tool

EDS Enquète Démographique et de Santé

CRA Comparative Risk Assessment

SES Socio Economic Strata

IQ Intelligence Quotient

PAF Population Attributable Fractions

RR Relative Risk

DW Disability Weight

CAF Franc d'Afrique Centrale

UNI-WIDER United Nations University - World Institute for Development Economics Research

SD Standard Deviation

RDA Recommended Daily Allowance

USD United States Dollar

PSA Probabilistic Sensitivity Analysis

Codex Alimentarius International Food Code

WHO World Health Organization

FAO Food and Agriculture Organization

NRV Nutrient Reference Values

RNI Recommended Nutrient Intakes

WRA Women in Reproductive Age

PIPAF Programme Ivoirien de la Promotion des Aliments Fortifiés

Hb Hemoglobin

\section{Declarations}

Ethics approval and consent to participate

Procedures and questionnaires for standard DHS surveys have been reviewed and approved by ICF Institutional Review Board (IRB). Additionally, country-specific DHS survey protocols are reviewed by the ICF IRB and typically by an IRB in the host country. ICF IRB ensures that the survey complies with the U.S. Department of Health and Human Services regulations for the protection of human subjects (45 CFR 46), while the host country IRB ensures that the survey complies with laws and norms of the nation.

Consent for publication

"Not applicable"

Availability of data and materials

The study is primary based on the raw data of the Demographic Health Survey 2012 in Côte D'Ivoire. Data are publically available on the DHS website https://www.dhsprogram.com. 


\section{Competing interests}

Dr. Prieto Patron, Dr. Detzel, Dr. Sabatier and Dr. Hutton are employed by Nestec SA, Nestlé Research Center. Prof. Giovanni Fattore, who leads a project sponsored by Nestec SA at Bocconi University on the economic evaluation methods for nutrition, did not receive any direct or indirect remuneration for his contribution to this work.

Funding

This study is part of the research project of assessing the impact of fortification at the Nestle Research Center. Four out of the five authors are workers of the Nestle Research Center.

Acknowledgments

"Not applicable"

Authors' contributions

APP conceptualized and designed the model, did the data analysis, drafted and revised the paper; PRD contributed to conceptualization and designed of the model, drafted and revised the paper; $\mathrm{ZH}$ and GF provided inputs for the model, drafted and revised the paper; MS calibrated the impact of fortification on hemoglobin, revised the paper. 
Appendix A. Calculation of production losses related to lower school performance

The calculations of production losses related to lower school performance are modeled by SES and by year cohort.

Calculation of production losses for children attending school with IDA who do not drop out of school: First we count the number of children at given age attending school in that year and multiply this with the prevalence of IDA of children at any given age. This determines the number of children with IDA at every year. Then this figure is multiplied by 0.1 , which is the estimated school loss for every student with IDA because of lower knowledge retention and higher absenteeism. The result is then multiplied by the average lifelong value of a year of education for a child at any given age. This is a function of several parameters including returns on education, expected future wages and working life span adjusted with a discount rate.

Calculation of production losses for children attending school with IDA who drop out of school: The total number of dropouts linked to IDA every school year is estimated using the Population Attributable Fraction. Then we calculate the years of school lost due to early school leaving. The result is multiplied by the average lifelong value of a year of education for a child at any given age, which is a function of various variables as listed before.

Appendix B. Underlying distributions and confidence intervals of the parameters for the Probabilistic Sensitivity Analysis

\begin{tabular}{|c|c|c|c|c|}
\hline Parameters & $\begin{array}{l}\text { Baseline } \\
\text { Values }\end{array}$ & $95 \% \mathrm{CI}$ & Distribution & References \\
\hline \multicolumn{5}{|l|}{ Share of anemia due to IDA } \\
\hline Pre-school-children \% & 64 & $(0.57: 0.70)$ & Beta & \\
\hline School age children $\%$ & 45 & $(0.39: 0.51)$ & Beta & Kassebaum, et al. and \\
\hline Women \% & 39 & $(0.34: 0.44)$ & Beta & Asorbayire, et al. [1, 5] \\
\hline Men $\%$ & 18 & $(0.15: 0.20)$ & Beta & \\
\hline \multicolumn{5}{|l|}{$\begin{array}{l}\text { Impact of anemia in preschool } \\
\text { children }\end{array}$} \\
\hline Relative risk of mortality & 2.19 & $(1.68: 3.36)$ & Lognormal & Brabin, et al. [37] \\
\hline IQ loss due to IDA (points) & 9 & $(5.1: 13.4)$ & Gamma & Lozoff, et al. [39] \\
\hline Impact of IQ losses on wages $\%$ & 8 & $(0.05: 0.01)$ & Beta & Psacharopoulos [55] \\
\hline $\begin{array}{l}\text { Intergeneration income } \\
\text { correlation }^{*}\end{array}$ & 0.55 & $(0.50: 0.59)$ & Beta & Black, Solon $[53,54]$ \\
\hline
\end{tabular}


Cont. Underlying distributions and confidence intervals of the parameters for the Probabilistic Sensitivity Analysis

\begin{tabular}{|c|c|c|c|c|}
\hline Parameters & $\begin{array}{l}\text { Baseline } \\
\text { Values }\end{array}$ & $95 \% \mathrm{CI}$ & Distribution & References \\
\hline \multicolumn{5}{|l|}{$\begin{array}{l}\text { Impact of anemia in school } \\
\text { children }\end{array}$} \\
\hline Relative risk to dropout (risk) & 1.25 & $(1.01: 1.45)$ & Lognormal & $\begin{array}{l}\text { Soemantri et al., } \\
\text { Hutchinson et al., } \\
\text { Bobonis et al., Walker } \\
\text { et al. [27, 29-31] }\end{array}$ \\
\hline Reduced learning at school \% & 10 & $(0.087: 0.116)$ & Beta & $\begin{array}{c}\text { Soemantri et al., } \\
\text { Hutchinson et al. } \\
{[29,30]}\end{array}$ \\
\hline $\begin{array}{l}\text { Intergeneration income } \\
\text { correlation* }\end{array}$ & 0.35 & $(0.31: 0.38)$ & Beta & Black [53] \\
\hline Returns on education \% & 10.9 & $(0.079: 0.139)$ & Lognormal $^{* *}$ & \\
\hline \multicolumn{5}{|l|}{$\begin{array}{l}\text { Impact of anemia in adults on } \\
\text { wages }\end{array}$} \\
\hline Moderate manual labor \% & 5 & $(0.045: 0.057)$ & Lognormal $^{* *}$ & \\
\hline $\begin{array}{l}\text { Additional loss intense manual } \\
\text { labor } \%\end{array}$ & 12 & $(0.110: 0.136)$ & Lognormal $^{* *}$ & Basta [56] \\
\hline \multicolumn{5}{|l|}{$\begin{array}{l}\text { Disability weights (DW) in } \\
\text { score units }\end{array}$} \\
\hline Anemia mild (DW) & 0.005 & $(0.002: 0.023)$ & Beta & \multirow{4}{*}{$\begin{array}{c}\text { Plessow et al. } \\
\text { Murray et al. } \\
{[42,43,45]}\end{array}$} \\
\hline Anemia moderate (DW) & 0.058 & $(0.038: 0.086)$ & Beta & \\
\hline Anemia severe (DW) & 0.164 & $(0.112: 0.228)$ & Beta & \\
\hline $\begin{array}{l}\text { Intellectual disability mild }(\mathrm{DW}) \\
\text { Intellectual disability moderate } \\
(\mathrm{DW})\end{array}$ & 0.031 & $(0.053: 0.114)$ & Beta & \\
\hline \multicolumn{5}{|l|}{ Other parameters } \\
\hline Life expectancy (years) & 58 & $(56.2: 60.8)$ & Gamma & World Factbook [47] \\
\hline Working life begins (years) & 15 & $(13.2: 18.1)$ & Gamma & World Bank [48] \\
\hline Working life ends (years) & 65 & $(60.6: 71.4)$ & Gamma & World Bank [48] \\
\hline Labor force participation $\%$ & 55 & $(0.497: 0.571)$ & Beta & World Bank [48] \\
\hline Projected income growth \% & 3.5 & $(0.039: 0.031)$ & Normal & World Bank [51] \\
\hline Interest rate $\%$ & 3 & $(0.034: 0.026)$ & Normal & Smith [50] \\
\hline $\begin{array}{l}\text { Mean monthly wage } \\
(C F A \mid 2015)\end{array}$ & $64^{\prime} 575$ & $\left(54^{\prime} 575: 74^{\prime} 575\right)$ & Gamma & $\begin{array}{c}\text { National Statistics Cote } \\
\text { D'Ivoire [49] }\end{array}$ \\
\hline
\end{tabular}


Appendix C. Table of the parameters used in the impact of fortified wheat flour and bouillon in hemoglobin in Côte D’Ivoire

\begin{tabular}{|c|c|c|c|}
\hline Parameter description & Value & $95 \% \mathrm{CI}$ & Reference \\
\hline \multicolumn{4}{|l|}{ Consumption per capita } \\
\hline Bouillon cubes WRA g/day & 3.7 & $(3.5: 3.9)$ & \multirow{4}{*}{ Rohner et al. [10] } \\
\hline Bouillon cubes $6-23 m$ g/day & 1.4 & $(1.2: 1.5)$ & \\
\hline Wheat flour a WRA g/day & 125 & $(112: 138)$ & \\
\hline Wheat flour a 6-23m g/day & 33 & $(29.2: 36.8)$ & \\
\hline \multicolumn{4}{|l|}{ RNI and mg of iron per capita in } \\
\hline \multicolumn{4}{|l|}{ WRA } \\
\hline Iron as \% of RNI from wheat flour & 17.8 & $(15.7: 19.8)$ & \multirow{4}{*}{ Rohner et al.[10] } \\
\hline Iron as \% of RNI from bouillon & 15.9 & $(14.2: 17: 4)$ & \\
\hline $\mathrm{Mg} / \mathrm{d}$ of iron from wheat flour & 2.634 & $(2.32: 2.93)$ & \\
\hline $\mathrm{Mg} / \mathrm{d}$ of iron from bouillon cube & 2.355 & $(2.01: 2.73)$ & \\
\hline \multicolumn{4}{|l|}{$\begin{array}{l}\text { RNI and } \mathrm{mg} \text { of iron from fortified } \\
\text { vehicle } 6-23 \mathrm{~m}\end{array}$} \\
\hline Iron as \% of RNI from wheat flour & 10.6 & $(12.2: 9.1)$ & \multirow{4}{*}{$\begin{array}{l}\text { Rohner et al. [10] and } \\
\text { WHO/FAO [70] }\end{array}$} \\
\hline Iron as \% of RNI from bouillon & 12.4 & $(10.9: 13.9)$ & \\
\hline $\mathrm{Mg} / \mathrm{d}$ of iron from wheat flour & 0.743 & $(0.54: 0.95)$ & \\
\hline $\mathrm{Mg} / \mathrm{d}$ of iron from bouillon cube & 0.891 & $(0.65: 1.23)$ & \\
\hline \multicolumn{4}{|l|}{$\begin{array}{l}\text { Recommended nutrient intakes } \\
\text { (RNIs) }\end{array}$} \\
\hline RNI iron WRA in $m g / d$ & 14.8 & & \multirow{2}{*}{ WHO/FAO [70] } \\
\hline RNI iron 6-23M in $\mathrm{mg} / \mathrm{d}$ & 7.2 & & \\
\hline \multicolumn{4}{|l|}{$\begin{array}{l}\text { Increase in hemoglobin due } \\
\text { to additional iron intake }\end{array}$} \\
\hline$\triangle \mathrm{Hb} g / \mathrm{L}$ in WRA from wheat flour & 1.034 & $(0.84: 1.24)$ & \multirow{6}{*}{$\begin{array}{c}\text { Own calculation based } \\
\text { Hess et al., } \\
\text { Winichangoon et al. } \\
{[57,58]}\end{array}$} \\
\hline$\Delta \mathrm{Hb} \mathrm{g} / \mathrm{L}$ in $6-23 \mathrm{~m}$ from wheat flour & 0.561 & $(0.45: 0.67)$ & \\
\hline$\Delta \mathrm{Hb} \mathrm{g} / \mathrm{L}$ in $24-59 \mathrm{~m}$ from wheat flour & 0.798 & $(0.65: 0.96)$ & \\
\hline$\triangle \mathrm{Hb} \mathrm{g} / \mathrm{L}$ in WRA from bouillon & 0.924 & $(0.75: 1.11)$ & \\
\hline$\Delta \mathrm{Hb} \mathrm{g} / \mathrm{L}$ in $6-23 m$ from bouillon & 0.673 & $(0.55: 0.81)$ & \\
\hline$\Delta \mathrm{Hb} \mathrm{g} / \mathrm{L}$ in $24-59 \mathrm{~m}$ from bouillon & 0.799 & $(0.65: 0.96)$ & \\
\hline
\end{tabular}


Appendix D. Tables using share of anemia attributed to Iron Deficiency by Petry et al.

Table D1. Economic burden: Production losses before and after iron fortification of wheat flour and condiments by age-groug using anemia attributed to iron deficiency by Petry et al.

\begin{tabular}{|c|c|c|c|c|}
\hline & $\begin{array}{l}\text { Pre-school } \\
\text { children }\end{array}$ & $\begin{array}{l}\text { School-aged } \\
\text { children }\end{array}$ & Adults & Total \\
\hline & \multicolumn{4}{|c|}{ million USD } \\
\hline After condiment \& flour fortification & 160.8 & 297.3 & 33.4 & 491.5 \\
\hline (mean $[95 \% \mathrm{CI}]$ ) & {$[101.5: 240.8]$} & [145.1 : 511.9] & {$[25.3: 42.6]$} & {$[312.5: 737.6]$} \\
\hline After flour and before condiment & 166.4 & 315.6 & 35.1 & 517 \\
\hline fortification (mean $(95 \% \mathrm{CI})$ ) & {$[105.3: 249.1]$} & {$[154.1: 542.9]$} & [26.6: 44.7] & {$[328.2: 776.4]$} \\
\hline \multirow{2}{*}{ Before flour fortification (mean $(95 \% \mathrm{CI})$ ) } & 171.2 & 336.3 & 36.9 & 544.5 \\
\hline & {$[108.4: 256.2]$} & {$[164.4: 578.1]$} & [28: 47] & {$[344.5: 818.3]$} \\
\hline $\begin{array}{l}\text { Absolute change attributable to flour } \\
\text { fortification (mean) }\end{array}$ & 4.8 & 20.7 & 1.8 & 27.5 \\
\hline \multirow{2}{*}{$\begin{array}{l}\text { Absolute change attributable to } \\
\text { condiment fortification (mean) }\end{array}$} & 5.6 & 18.3 & 1.7 & 25.5 \\
\hline & & $\%$ change & & \\
\hline $\begin{array}{l}\text { Reduction attributable to flour } \\
\text { fortification }\end{array}$ & $2.80 \%$ & $6.16 \%$ & $4.88 \%$ & $5.05 \%$ \\
\hline $\begin{array}{l}\text { Reduction attributable to condiment } \\
\text { fortification }\end{array}$ & $3.48 \%$ & $6.16 \%$ & $5.09 \%$ & $5.19 \%$ \\
\hline
\end{tabular}

CI: confidence interval. This refers to constructed $95 \%$ confidence intervals as calculated in the probabilistic sensitivity analysis. Pre-school children: 0.5 to 4 years; School age children: 5 to 14 years: Adult men and women: 15 to 64 years.

Using the attribution of anemia to iron deficiency of $25 \%$ for pre-school age children and $30 \%$ for school age children, $37 \%$ for women and $18 \%$ for men by Petry et al. [4]

Table D2. Health burden: disability adjusted life years (DALYs) before and after iron fortification of wheat flour and condiments by age-group using lower share of anemia attributed to iron deficiency.

\begin{tabular}{|c|c|c|c|c|}
\hline & $\begin{array}{l}\text { Pre-school } \\
\text { children }\end{array}$ & $\begin{array}{l}\text { School-aged } \\
\text { children }\end{array}$ & Adults & Total \\
\hline \multicolumn{5}{|c|}{ DISCOUNTED HEALTH BURDEN } \\
\hline \multirow{3}{*}{$\begin{array}{l}\text { After condiment \& flour fortification } \\
(\text { mean }[95 \% \mathrm{CI}])\end{array}$} & \multicolumn{4}{|c|}{ ‘000 DALYs } \\
\hline & 47.8 & 29.2 & 46.8 & 123.8 \\
\hline & {$[36.9: 60.5]$} & {$[16.3: 45.7]$} & {$[27.9: 70.4]$} & {$[86: 170.3]$} \\
\hline After flour and before condiment & 50.3 & 31.5 & 50.1 & 131.9 \\
\hline fortification (mean $[95 \% \mathrm{CI}]$ ) & {$[39: 63.6]$} & {$[17.7: 49.3]$} & {$[30: 75.3]$} & [91.8: 181.5] \\
\hline \multirow{2}{*}{ Before flour fortification (mean $[95 \% \mathrm{CI}]$ ) } & 52.6 & 34.2 & 54 & 140.9 \\
\hline & {$[40.9: 66.5]$} & {$[19.2: 53.4]$} & {$[32.4: 81.1]$} & [98: 193.8] \\
\hline $\begin{array}{l}\text { Absolute change attributable to flour } \\
\text { fortification (mean) }\end{array}$ & 2.3 & 2.7 & 3.9 & 9 \\
\hline \multirow[t]{2}{*}{$\begin{array}{l}\text { Absolute change attributable to } \\
\text { condiment fortification (mean) }\end{array}$} & 2.5 & 2.3 & 3.3 & 8.1 \\
\hline & \multicolumn{4}{|c|}{$\%$ change } \\
\hline
\end{tabular}


Reduction attributable to flour fortification
$4.37 \%$

$7.89 \%$

$4.97 \%$

$7.30 \%$

$6.59 \%$

$6.14 \%$

$7.22 \%$

$6.39 \%$ fortification

DALYs: disability adjusted life years; CI: confidence interval. This refers to constructed $95 \%$ confidence intervals as calculated in the probabilistic sensitivity analysis. Pre-school children from 0.5 to 4 years old; School age children from 5 to 14 years old: Adults men and women from 15 to 64 years old.

Using the attribution of anemia to iron deficinecy of $25 \%$ for pre-school age children and $30 \%$ for school age children, $37 \%$ for women and $18 \%$ for men by Petry et al. [4] 


\section{References}

1. Kassebaum, N.J., et al., A systematic analysis of global anemia burden from 1990 to 2010. Blood, 2014. 123: p. 615-24 DOI: 10.1182/blood-2013-06-508325.

2. Salomon, J.A., et al., Common values in assessing health outcomes from disease and injury: disability weights measurement study for the Global Burden of Disease Study 2010. Lancet, 2012. 380: p. 2129-43 DOI: 10.1016/s0140-6736(12)61680-8.

3. The, L., GBD 2015: from big data to meaningful change. Lancet, 2016. 388: p. 1447 DOI: 10.1016/s01406736(16)31790-1.

4. Petry, N., et al., The proportion of anemia associated with iron deficiency in low, medium, and high human development index countries: a systematic analysis of national surveys. Nutrients, 2016. 8: p. 693.

5. Asobayire, F.S., et al., Prevalence of iron deficiency with and without concurrent anemia in population groups with high prevalences of malaria and other infections: a study in Cote d'Ivoire. Am J Clin Nutr, 2001. 74: p. 776-82.

6. Alderman, H. and S. Linnemayr, Anemia in low-income countries is unlikely to be addressed by economic development without additional programs. Food and nutrition bulletin, 2009. 30: p. 265-269.

7. Santeramo, F.G. and N. Shabnam, The income-elasticity of calories, macro-and micro-nutrients: What is the literature telling us? Food Research International, 2015. 76: p. 932-937.

8. Bhargava, A., Iron status, malaria parasite loads and food policies: evidence from sub-Saharan Africa. Econ Hum Biol, 2013. 11: p. 108-12 DOI: 10.1016/j.ehb.2012.02.004.

9. Republique de Cote D'Ivoire, Politique National de Nutrition. 2015, Ministre de la Sante et de l'Hygiene Publique: Cote D'Ivoire. p. 32.

10. Rohner, F., et al., The Potential of Food Fortification to Add Micronutrients in Young Children and Women of Reproductive Age - Findings from a Cross-Sectional Survey in Abidjan, Cote d'Ivoire. PLoS One, 2016. 11: p. e0158552 DOI: 10.1371/journal.pone.0158552.

11. Acuin CCS, P.L., Duante C, Serafico M, Ducay AJ, Campanzana M, Reducing Micronutrient Deficiencies in a Decentralized Setting: Lessons in Food Fortification from the Philippines. FASEB J, 2016. 30: p. 892.16.

12. Martorell, R., et al., Effectiveness evaluation of the food fortification program of Costa Rica: impact on anemia prevalence and hemoglobin concentrations in women and children. Am J Clin Nutr, 2015. 101: p. 210-7 DOI: 10.3945/ajcn.114.097709.

13. Nik Shanita S, et al., Prevalence of Anaemia and Iron Deficiency among Primary Schoolchildren in Malaysia. International journal of environmental research and public health. 2018 Nov;15(11):2332. DOI: 10.3390/ijerph15112332

14. Ramírez-Vélez R, et al., Ferritin levels in Colombian children: findings from the 2010 National Nutrition Survey (ENSIN). International journal of environmental research and public health. 2016 Apr;13(4):405. DOI: 10.3390/ijerph13040405

15. Wu J, Hu Y, et al., Prevalence of Anemia in Chinese Children and Adolescents and Its Associated Factors. International journal of environmental research and public health. 2019 Jan;16(8):1416. DOI: 10.3390/ijerph16081416

16. Rohner, F., et al., The Effects of an Oil and Wheat Flour Fortification Program on Pre-School Children and Women of Reproductive Age Living in Cote d'Ivoire, a Malaria-Endemic Area. Nutrients, 2016. 8: p. 148 DOI: $10.3390 /$ nu8030148.

17. Allen L, et al., Guidelines on food fortification with micronutrients. World Health Organization/Food 
and Agricultural Organization of the United Nations, 2006. WHO Library: p. ISBN 92-4-159401-2.

18. Das, J.K., et al., Micronutrient fortification of food and its impact on woman and child health: a systematic review. Syst Rev, 2013. 2: p. 67 DOI: 10.1186/2046-4053-2-67.

19. Moench-Pfanner, R. and M.W. Bloem, ASEAN: insights and considerations toward nutrition programs. Food Nutr Bull, 2013. 34: p. S4-7 DOI: 10.1177/15648265130342S102.

20. Hess, S.Y., et al., Results of Fortification Rapid Assessment Tool (FRAT) surveys in sub-Saharan Africa and suggestions for future modifications of the survey instrument. Food Nutr Bull, 2013. 34: p. 21-38 DOI: $10.1177 / 156482651303400104$.

21. de Mejia, E.G., et al., Industrial processing of condiments and seasonings and its implications for micronutrient fortification. Ann N Y Acad Sci, 2015. 1357: p. 8-28 DOI: 10.1111/nyas.12869.

22. GAIN. Nigeria. [cited 2017 07.20]; Available from: http://www.gainhealth.org/knowledgecentre/country/nigeria/.

23. Briggs, A.D., et al., Choosing an epidemiological model structure for the economic evaluation of noncommunicable disease public health interventions. Popul Health Metr, 2016. 14: p. 17 DOI: 10.1186/s12963016-0085-1.

24. Wieser, S., et al., Burden of micronutrient deficiencies by socio-economic strata in children aged 6 months to 5 years in the Philippines. BMC Public Health, 2013. 13: p. 1167 DOI: 10.1186/1471-2458-13-1167.

25. Bagriansky, J., et al., The economic consequences of malnutrition in Cambodia, more than 400 million US dollar lost annually. Asia Pac J Clin Nutr, 2014. 23: p. 524-31 DOI: 10.6133/apjen.2014.23.4.08.

26. Alcázar, L., Impacto económico de la anemia en el Perú. 2012, GRADE; Acción contra el Hambre.

27. Bobonis, G.J., E. Miguel, and C.P. Sharma, Iron deficiency anemia and school participation. Poverty Action 2004. Lab Paper: p. 1118-1120.

28. Chong, A., et al., Iron deficiency and schooling attainment in peru. American Economic Journal: Applied Economics, 2016. 8: p. 222-255.

29. Hutchinson, S.E., et al., Nutrition, anaemia, geohelminth infection and school achievement in rural Jamaican primary school children. Eur J Clin Nutr, 1997. 51: p. 729-35.

30. Soemantri, A.G., E. Pollitt, and I. Kim, Iron deficiency anemia and educational achievement. Am J Clin Nutr, 1985. 42: p. 1221-8.

31. Walker, S.P., et al., School performance in adolescent Jamaican girls: associations with health, social and behavioural characteristics, and risk factors for dropout. J Adolesc, 1998. 21: p. 109-22 DOI: 10.1006/jado.1997.0133.

32. Psacharopoulos, G. and H.A. Patrinos, Returns to investment in education: A further update. Education Economics, 2004. 12: p. 111-134.

33. Ba, I., Le Recensement Général de la Population et de l'Habitation de Côte d'Ivoire de 2014. (RGPH-14), Rapport d'execution et presentation des principaux résultats. 2015, Institute National de la Statistique: Abidjan. 34. Engle-Stone, R., et al., Predictors of anemia in preschool children: Biomarkers Reflecting Inflammation and Nutritional Determinants of Anemia (BRINDA) project. The American journal of clinical nutrition, 2017. 106: p. 402S-415S.

35. Merrill, R.D., et al., Factors associated with inflammation in preschool children and women of reproductive age: Biomarkers Reflecting Inflammation and Nutritional Determinants of Anemia (BRINDA) project. The American journal of clinical nutrition, 2017. 106: p. 348S-358S.

36. Wirth, J.P., et al., Predictors of anemia in women of reproductive age: Biomarkers Reflecting Inflammation and Nutritional Determinants of Anemia (BRINDA) project. The American journal of clinical nutrition, 2017. 106: p. 416S-427S. 
37. Brabin, B.J., Z. Premji, and F. Verhoeff, An analysis of anemia and child mortality. J Nutr, 2001. 131: p. 636S-645S; discussion 646S-648S.

38. Camaschella, C., Iron-Deficiency Anemia. $N$ Engl J Med, 2015. 373: p. 485-6 DOI: 10.1056/NEJMc1507104.

39. Lozoff, B., E. Jimenez, and J.B. Smith, Double burden of iron deficiency in infancy and low socioeconomic status: a longitudinal analysis of cognitive test scores to age 19 years. Arch Pediatr Adolesc Med, 2006. 160: p. 1108-13 DOI: 10.1001/archpedi.160.11.1108.

40. Vos, T., et al., Years lived with disability (YLDs) for 1160 sequelae of 289 diseases and injuries 19902010: a systematic analysis for the Global Burden of Disease Study 2010. Lancet, 2012. 380: p. 2163-96 DOI: 10.1016/s0140-6736(12)61729-2.

41. WHO, UNICEF, and UNU, Iron Deficiency Anaemia Assessment, Prevention, and Control. A guide for programme managers. 2001, WHO, UNICEF, UNU: Geneva.

42. Murray, C.J., A.D. Lopez, and W.H. Organization, The global burden of disease: a comprehensive assessment of mortality and disability from diseases, injuries, and risk factors in 1990 and projected to 2020: summary. 1996.

43. Plessow, R., et al., Social Costs of Iron Deficiency Anemia in 6-59-Month-Old Children in India. PLoS One, 2015. 10: p. e0136581 DOI: 10.1371/journal.pone.0136581.

44. Stein AJ, M.J., Qaim M, Nestel P, Sachdev HPS, Bhutta ZA,, Analyzing the health benefits of biofortified staple crops by means of the disability-adjusted life years approach: A handbook focusing on iron, zinc and vitamin A. HarvestPlus Technical Monographs, 2005. International Food Policy Research Institute: p. 32.

45. Murray, C.J., et al., Disability-adjusted life years (DALYs) for 291 diseases and injuries in 21 regions, 1990-2010: a systematic analysis for the Global Burden of Disease Study 2010. The lancet, 2012. 380: p. 21972223 DOI: 10.1016/S0140-6736(12)61689-4.

46. Horton, S. and J. Ross, The economics of iron deficiency. Food policy, 2003. 28: p. 51-75.

47. Central Intelligence Agency, The World Factbook 2016-17. Washington DC, 2016.

48. World Bank, World Development Indicators World Data Bank. 2016.

49. l'Institut National de la Statistique de la Côte d'Ivoire, Enquête sur le Niveau de Vie des Ménages en Côte D'Ivoire. Abidjan, 2015.

50. Smith, D. and H. Gravelle, The practice of discounting economic evaluation of health care interventions. University of York, 2000. Centre for Health Economics.

51. WB Group, Global Economic Prospects, January 2016: Spillovers Amid Weak Growth. World Bank, 2016. Washington D.C.

52. UNI-WIDER, World Income Inequality Database. WIID, 2015. 3.3: p. https://www.wider.unu.edu/project/wiid-world-income-inequality-database.

53. Black SE, D.P., Recent developments in intergenerational mobility. National Bureau of Economic Research, 2010. NBER Working Paper p. No. 15889.

54. Solon G, Cross-country differences in intergenerational earnings mobility. The Journal of Economic Perspectives 2002. 16: p. 59-66.

55. Psacharopoulos, G. and E. Velez, Schooling, ability, and earnings in Colombia 1988. Economic Development and Cultural Change 1988. 40: p. 629-643.

56. Basta, S.S., et al., Iron deficiency anemia and the productivity of adult males in Indonesia. Am J Clin Nutr, 1979. 32: p. 916-25.

57. Hess, S., L. Tecklenburg, and K. Eichler, Micronutrient Fortified Condiments and Noodles to Reduce 
Anemia in Children and Adults--A Literature Review and Meta-Analysis. Nutrients, 2016. 8: p. 88 DOI: 10.3390/nu8020088.

58. Winichagoon, P., et al., A multimicronutrient-fortified seasoning powder enhances the hemoglobin, zinc, and iodine status of primary school children in North East Thailand: a randomized controlled trial of efficacy. J Nutr, 2006. 136: p. 1617-23.

59. Andersson, M., et al., Dual fortification of salt with iodine and iron: a randomized, double-blind, controlled trial of micronized ferric pyrophosphate and encapsulated ferrous fumarate in southern India. Am J Clin Nutr, 2008. 88: p. 1378-87.

60. Zimmermann, M.B., et al., Dual fortification of salt with iodine and micronized ferric pyrophosphate: a randomized, double-blind, controlled trial. Am J Clin Nutr, 2004. 80: p. 952-9.

61. Cook, J.D. and M.E. Reusser, Iron fortification: an update. Am J Clin Nutr, 1983. 38: p. 648-59.

62. Hurrell, R., Linking the bioavailability of iron compounds to the efficacy of iron-fortified foods. Int $J$ Vitam Nutr Res, 2007. 77: p. 166-73 DOI: 10.1024/0300-9831.77.3.166.

63. Michelazzo, F.B., et al., The influence of vitamin A supplementation on iron status. Nutrients, 2013. 5 : p. 4399-413 DOI: 10.3390/nu5114399.

64. Powers, H.J., Riboflavin-iron interactions with particular emphasis on the gastrointestinal tract. Proc Nutr Soc, 1995. 54: p. 509-17.

65. Wegmüller R, et al., Salt dual-fortified with iodine and micronized ground ferric pyrophosphate affects iron status but not hemoglobin in children in Cote d'Ivoire. J Nutr, 2006. 136: p. 1814-20.

66. Oyelere, R.U., Understanding low average returns to education in Africa: the role of heterogeneity across education levels and the importance of political and economic reforms. 2008: Citeseer.

67. Aaron, G.J., et al., Coverage of Large-Scale Food Fortification of Edible Oil, Wheat Flour, and Maize Flour Varies Greatly by Vehicle and Country but Is Consistently Lower among the Most Vulnerable: Results from Coverage Surveys in 8 Countries-3. The Journal of nutrition, 2017. 147: p. 984S-994S.

68. Spohrer, R., et al., The growing importance of staple foods and condiments used as ingredients in the food industry and implications for large-scale food fortification programs in Southeast Asia. Food Nutr Bull, 2013. 34: p. S50-61 DOI: 10.1177/15648265130342S107.

69. Darnton-Hill, I., et al., Large-scale food fortification: an overview of trends and challenges in low and middleincome countries in 2017, M. Forum, Editor. 2017, Micronutrient Forum.

70. Joint, F. and W.H. O., Vitamin and mineral requirements in human nutrition. 2005.

1. 